\title{
Supporting mobile education for pre-service teachers
}

\author{
C. Paul Newhouse, P. John Williams and Jennifer Pearson \\ Edith Cowan University
}

\begin{abstract}
Mobile computing devices are increasingly finding a place in universities, putting the pressure on teacher education to consider how best to incorporate the use of these technologies. At the same time there is pressure from the requirement for teacher education students to develop skills and experience in using digital technologies to support their teaching in schools. In response to these pressures the School of Education at Edith Cowan University has involved students in two exploratory projects over the past two years concerned with the use of laptop computers. This paper reports on the implementation and results of these projects. While generally the outcomes were positive it is not clear that this is the preferred solution when considering the range of digital device options available.
\end{abstract}

For over four decades computer systems have found an increasing role in educational institutions, particularly over the past 15 years with the growth of Internet based applications (e.g. Chen \& Kinshuk., 2005). At the same time education has become a life long activity, as increasingly people aim to undertake study related activities anytime and anywhere they find suitable for their life and work requirements. While the use of Internet based educational applications in universities has helped satisfy some of this flexibility requirement, the recent emergence of a range of mobile technologies may hasten this process for learners in tertiary institutions. The use of mobile digital devices from wirelessly networked laptops to iPods, personal digital assistants (PDAs), Tablet PCs or advanced mobile phones is a growing trend on university campuses (Galuszka, 2005). These devices are becoming more portable and affordable, making them a more realistic proposition for universities to consider. Their advantages include convenience, with the ability to communicate and access course materials just about anywhere, and all provide ways to carry significant volumes of information.

According to Virvou and Alepis (2005), one important field in which mobile technology can make significant contributions is teacher education. 
Several studies (e.g. Riggsby, 1998) have demonstrated the great promise of mobile learning for pre-service teacher education using various digital devices. However, the relative merits of each of these devices needs to be considered and weighed against the requirements of teacher education courses and student life at an Australian university. This paper sets out to introduce learning with mobile devices and discusses the results of exploratory studies at Edith Cowan University using wireless laptop computers.

\section{Mobile education and teacher education}

Online learning using Internet based technologies has become an important feature of programs at tertiary institutions, with the rationale that this supports student learning beyond physical classrooms. Learning with mobile devices promises continued extension towards "anywhere, anytime", or mobile, learning (Houser, Thornton \& Kluge, 2002). Mobile devices perform many of the functions of desktop computers, with the advantages of being easier to learn to use and easier to access anywhere, anytime, due to their portability. Lehner and Nosekabel (2002) define "mobile education" as "any service or facility that supplies a learner with general electronic information and educational content that aids in acquisition of knowledge regardless of location and time." Vavoula and Sharples (2002) postulate "three ways in which learning can be considered mobile: learning is mobile in terms of space; it is mobile in different areas of life; it is mobile with respect to time." For example, access to other students and the instructor allows for collaboration and instant feedback for group projects outside of class time, and can strengthen faculty interactions with students, especially those students who are hesitant to participate in traditional classroom discussions (Partee, 1996). The privacy, portability, and constant availability of mobile technologies allow students to use them for their own personal life activities as well as at university, giving a higher degree of autonomy (Kariuki \& Turner, 2001). Due to the portable nature of the devices, instructors are able to undertake more inquiry oriented and project based activities with the students (McMillan \& Honey, 1993, p. 40). Finally, this is all likely to increase student motivation and achievement (Gottfried \& McFeely, 1998).

A critical question needing to be addressed is the role that the technologies may play in mobile education, from replacing other technologies in the traditional classroom (e.g. lecture notes are distributed electronically), to supporting new or revised learning activities (e.g. shared documents in group projects). The traditional classroom only supports activities that are carried out at a designated place and time. Desktop computers have been used for many years to extend the range of options to places where wired connection is accessible, such as at home. Now with mobile technologies, 
the range of education can be further extended by wireless connection to places and time of learners' choice. The shift from desktop to mobile technologies has great potential for facilitating an increased range of learning activities, that increase the efficiency of educational information exchange between the learners and the teachers (Chen \& Kinshuk, 2005). There are now a range of types of mobile devices that could provide such support for learning programs in tertiary institutions, including PDAs, limited purpose 'player' devices (e.g. iPod), mobile phones and laptop computers. The first device usually considered is the laptop computer and this was the case at Edith Cowan University for a number of pilot projects.

From the late 1980s full microcomputer systems have been developed that are intended to be portable and personal. These variously are called laptop or notebook computers and have progressively become more powerful (equivalent processing to desktop computer systems), flexible (e.g. Tablet PC with stylus input) and more portable (lighter, wireless communications and with longer battery life). However, they are always more expensive than equivalent desktop computer systems. A clear aim in the development of laptop computers was to adapt to 'work with the user' and therefore educators have considered how this may apply to the way people learn (Rideout, 2002). In a literature review conducted by Roschelle et al. (2004), 26 studies were identified that reported a range of benefits of using these technologies, such as, greater student engagement, increased understanding of complex subject matter, increased interest and enjoyment, heightened discussion and interactivity, and increased teacher insight into student difficulties.

The use of laptop computers is introduced in teacher education for a range of reasons, including: providing greater access to digital resources (Deden, 1998); improving students' IT skills development (Deden, 1998); enhancing learning opportunities (Mackinnon, 2001); improving services to all students (Cartwright, 1997); increasing equity of access to information (Finn \& Inman, 2004); improving institutional competitiveness (Brown, 2003); and increasing the convenience of access to computer technology students (Finn \& Inman, 2004). As Bradshow and Massey (1996, p. 4) have reported, laptops in the hands of students offer a convenient alternative to a computer laboratory with its administrative and technical overheads, networking equipment, custodial and building costs. At the University of Hong Kong over 2000 new undergraduate students participated in a laptop program for three years where it was reported that they were used for about 14 hours a week, and that most students were keen to continue and preferred laptops to desktops (Blurton \& Lee, 2002). However, it was also found that most students generally did not bring the laptops to campus owing to size and weight problems. 
Among university students, pre-service teachers have attracted particular attention when it comes to equipping students with laptop computers, due to the dual purpose of enhancing their own learning while introducing them to an instructional tool for their practice in schools (Riggsby, 1998; Schrum \& Dehoney, 1998). Research has shown a number of important benefits concerning overcoming distance barriers and efficiency in the use of time, particularly while students are engaged in their school based practicum (Kariuki \& Turner, 2001). For example, Thomas, Larson, Clift, and Levin (1996) found that pre-service teachers were able to communicate with their mentor teachers about the next day's lessons, share reflections on a previous day's activities, exchange teaching materials such as copies of quizzes, and so on, through the use of laptops. The students were also able to get quick help from their instructors, enabling them to proceed with more comfort, ease, and speed. In the School of Education at Columbus State University, Georgia, laptops were chosen in this case because they were seen as a "near perfect means" of equipping student teachers with portable technology that would allow them to execute their student responsibilities while in the field, and at the same time retain contact with their supervisors at the university (Riggsby, 1998, p. 5).

The findings of Kariuki and Turner's (2001) study indicated that laptops are a viable means of achieving several goals at the same time. These included giving pre-service teachers quick access to technology, offering them opportunities to develop confidence in the integration of technology in teaching, to become comfortable and effective participants in the information age, and to provide classroom teachers with an example of how technology can be used. Pre-service teachers who used laptop computers have been reported to have both more confidence in their ability as technology users, and a more positive attitude toward technology use as educators (Schrum \& Dehoney, 1998, p. 31). Students have reported that laptop computers are instrumental in building their computer skills and their confidence in these skills (Thompson, Schmidt \& Davis, 2003). Further, Riggsby (1998) indicated that laptop computers have been viewed as an efficient means of administering the development of electronic portfolios as part of an electronic resume that was then useful in gaining employment.

\section{Exploratory studies at Edith Cowan University}

During 2004 and 2005 pilot projects in the use of laptop computers were run at Edith Cowan University under the banner of the ECU Advantage Project. This project also involved the rollout of a wireless network across all campuses. Two such projects were run in the School of Education, with primary pre-service teachers, the first as part of a technology education 
unit in the second semester of 2004 and the second as part of a multi literacy unit in the first semester of 2005.

The range of outcomes expected from the project included assisting students to achieve successful learning outcomes in an exciting and stimulating fashion; developing confidence, knowledge and skills in the selection and application of ICTs; developing new teaching and learning models; enhancing flexible delivery options for staff and students; achieving an institutional advantage; and making more efficient use of space.

\section{Supporting technology education}

During the second half of 2004 IBM laptop computers were loaned to 50 teacher education students who were enrolled in a third year Bachelor of Education (Primary) unit of study, Technology and Enterprise Education. The class comprised primary pre-service teachers studying their compulsory technology education unit in the third year of their four year Bachelor of Education degree. There were a total of 270 students in the unit, who were divided into groups of 40-50, and it was one of these groups that was presented with laptop computers for their use throughout the 12-week semester. The building in which classes were held was equipped with a wireless network.

The compulsory unit Technology and Enterprise Education provides an introduction to the Technology and Enterprise Learning Area. Its aim is to develop students' confidence and competence in the use of a range of resources to solve problems and resolve issues in an enterprising manner. The philosophical basis and values of the learning area are explored through rich tasks. Students meet for three hours each week in groups of 40-50 and move between a workshop and computer lab, depending on the activity in which they are engaged. Two lecturers teach concurrently, one in the workshop and one in the computer lab. The assessment tasks for the semester include two assignments and an exam. The second assignment is an electronic portfolio which represents the student's learning journey throughout the semester. It includes evidence of a range of IT skills, documentation of the design processes followed in the workshop tasks, and reflections on progress and achievement.

The research rationale was to embed the collection of the data for the research into normal class activities, in order to avoid possible 'research effects' from skewing the results, although the research group did already feel 'special' as a result of the allocation of laptops to just the one group. For this reason the conceptual framework for the research was related to the underpinning philosophy of the unit. This philosophy could be termed 
critical constructivism - meaningful, creative, challenging, inquiry based and involving the active applications of educational technology, described as a 'technorealism' approach by Walker and White (2002). This approach is particularly appropriate for technology education at ECU, where the elements of critical constructivism are quite naturally embedded in classroom approaches: an active approach to learning, the development of a critical approach to technologies, and a 'designerly' approach to processes. Aligned with this is an applied system framework (Mathiason, 2004), encompassing the concepts of ICT (the instrument and the communication media), teaching (communication that intends to induce change) and learning (the deconstruction, construction and reconstruction of communication). The effectiveness of the system, represented by these three elements, becomes the broad focus of the research. A range of qualitative and quantitative data was collected in order to analyse the impact of the project on the participants.

The two unit lecturers were provided with technical and professional support to further develop the unit to effectively integrate a range of rich tasks, and so provide a seamless interface between the workshop and computer laboratory components. Each student was provided with an IBM R-series Thinkpad Laptop R50-1829-EMO, with Firewire card and CD burner added (USB ports came standard) weighing about $3 \mathrm{~kg}$. Software was installed on the laptops according to the needs of the unit and included Microsoft Windows XP, Microsoft Office, 3D Home Architect, Robolab, Kidspiration, Inspiration, KidPix, Smartboard, Windows Media Player 9 and Windows Movie Maker 2. A well padded backpack was also supplied to facilitate carrying the laptop and cables.

\section{Results from this project}

The students involved in the project were typical of the demographic preparing to be primary teachers: mainly females over 25 years old. Of the students in the group, $74 \%$ rated themselves as a regular computer user, and rated their level of computer expertise as $25 \%$ inexperienced, $62 \%$ experienced and $13 \%$ as very experienced.

During the unit of study students were asked to audit their ICT skills associated with the operation of personal computers, networks, peripheral devices (cameras, scanners and printers) and particular pieces of software including: WindowsXP, Powerpoint, Kidspiration, Inspiration, Word, Photo Editor, Kidpix, Movie Maker, and Robolab. The audit included the use of a skills checklist in the first and last weeks of the semester. The Week 1 experience provided a base of self understanding which was used as a comparison later in the semester (Table 1). A comparison was made between the laptop group (treatment) and the rest of the students in the 
unit (control) in terms of the ratings they gave themselves on some of the ICT skill items. Students were asked to respond to each skill by checking the box to indicate not at all skilled, quite skilled or very skilled. Each of these responses was nominated a numerical value of 1 (not at all), 2 or 3 (very) and means were calculated (Table 1 ). The Week 1 ratings indicated no significant differences between the treatment and control groups. As would be expected, all the ratings increase from Week 1 to Week 10 for both groups, indicating that students generally feel they are more experienced with ICT skills by the end of the semester. For all the ICT skills listed in Table 2 apart from one, the increase is greater for the laptop group than for the control group but using $t$ tests the differences were not found to be statistically significant.

Table 1: ICT skills self assessment ratings $(n=45)$

\begin{tabular}{|c|c|c|c|c|}
\hline Item & Group & Week 1 & Week 10 & Diff \\
\hline \multirow[t]{2}{*}{ Log onto the Internet } & $\mathrm{T}$ & 2.77 & 3.00 & 0.23 \\
\hline & $\mathrm{C}$ & 2.80 & 2.98 & 0.18 \\
\hline \multirow[t]{2}{*}{ Access Blackboard } & $\mathrm{T}$ & 2.64 & 3.00 & 0.36 \\
\hline & C & 2.74 & 2.95 & 0.21 \\
\hline \multirow[t]{2}{*}{ Download files from Blackboard } & $\mathrm{T}$ & 2.18 & 2.88 & 0.69 \\
\hline & C & 2.46 & 2.94 & 0.48 \\
\hline \multirow[t]{2}{*}{ Insert sound into PowerPoint } & $\mathrm{T}$ & 1.80 & 2.63 & 0.83 \\
\hline & $\mathrm{C}$ & 1.78 & 2.68 & 0.90 \\
\hline \multirow[t]{2}{*}{ Use Kidspiration and Inspiration } & $\mathrm{T}$ & 1.23 & 2.88 & 1.65 \\
\hline & $\mathrm{C}$ & 1.43 & 2.77 & 1.33 \\
\hline \multirow[t]{2}{*}{ Manipulate images with Photoeditor } & $\mathrm{T}$ & 1.48 & 2.50 & 1.02 \\
\hline & C & 1.47 & 2.48 & 1.01 \\
\hline \multirow[t]{2}{*}{ Create a QuickTime movie } & $\mathrm{T}$ & 1.05 & 2.65 & 1.60 \\
\hline & $\mathrm{C}$ & 1.08 & 2.55 & 1.47 \\
\hline \multirow[t]{2}{*}{ Line and clip viewer in Moviemaker } & $\mathrm{T}$ & 1.00 & 2.35 & 1.35 \\
\hline & C & 1.07 & 2.32 & 1.25 \\
\hline \multirow[t]{2}{*}{ Export file as QuickTime movie } & $\mathrm{T}$ & 1.00 & 2.38 & 1.38 \\
\hline & $\mathrm{C}$ & 1.08 & 2.35 & 1.27 \\
\hline
\end{tabular}

Ratings are on a scale of 1-3, from not at all skilled to very skilled.

Group: $\mathrm{T}=$ Treatment (laptop group), $\mathrm{C}=$ Control

An additional survey was given to students at the end of the semester to ascertain the effect of their experience with the technology. The students were required to rate statements from strongly disagree (1) to strongly agree (4). The mean ordered responses from 42 students with laptops are presented in Table 2. The results indicate that students felt the use of a laptop computer assisted them in their learning, by providing increased access to resources and helping them to be independent and better organised. The feeling that it enhanced communication with the lecturer or with other students was not as strong. This seemed to conflict with the finding that $77 \%$ of students used their laptop for group work. Most of the 
students experienced some kind of frustration throughout the semester, many in the initial stages of setting up the system and having all the required software working properly.

Table 2: Survey of laptop group outcomes $(n=45)$

\begin{tabular}{|l|c|c|}
\hline \multicolumn{1}{|c|}{ Statement } & $\begin{array}{c}\text { \% agree } \\
\text { (3-4 rating) }\end{array}$ & $\begin{array}{c}\text { Mean } \\
\text { response }\end{array}$ \\
\hline $\begin{array}{l}\text { The laptop increased the resources available to me as a } \\
\text { learner }\end{array}$ & 100 & 3.6 \\
\hline $\begin{array}{l}\text { The learning activities involving the use of the laptop were } \\
\text { usually exciting and stimulating }\end{array}$ & 100 & 3.3 \\
\hline $\begin{array}{l}\text { The laptop enabled me to complete learning tasks as an } \\
\text { independent learner }\end{array}$ & 97 & 3.5 \\
\hline $\begin{array}{l}\text { The laptop has assisted me in my learning } \\
\text { The laptop enabled me to become better organised as a } \\
\text { student in this unit }\end{array}$ & 93 & 3.7 \\
\hline $\begin{array}{l}\text { Use of the laptop in lectures/tutorials assisted my learning } \\
\text { in the unit }\end{array}$ & 90 & 3.4 \\
\hline $\begin{array}{l}\text { After the experience of using a laptop I would now like to } \\
\text { purchase my own laptop. }\end{array}$ & 89 & 3.4 \\
\hline $\begin{array}{l}\text { The laptop supported activities that reflected the way } \\
\text { knowledge is used in real life settings }\end{array}$ & 84 & 3.2 \\
\hline $\begin{array}{l}\text { Access to a wireless environment increased my use of web } \\
\text { based resources }\end{array}$ & 82 & 3.2 \\
\hline $\begin{array}{l}\text { The laptop facilitated communication between staff and } \\
\text { students }\end{array}$ & 81 & 3.1 \\
\hline $\begin{array}{l}\text { The laptop enabled meaningful communication with other } \\
\text { students }\end{array}$ & 72 \\
\hline $\begin{array}{l}\text { I have experienced frustration using the laptop for tasks set } \\
\text { by the lecturer }\end{array}$ & 69 & 2.9 \\
\hline
\end{tabular}

An analysis was also conducted on the final assessments the students received. There were two assessment tasks and an examination for the unit. While no significant difference was found between the two groups on any of the scores, it is interesting to note that the mean of the laptop group was consistently lower than the other students in the unit, as illustrated in Table 3. This seems to conflict with the advantage cited by a number of students that they could complete assignments to a higher standard.

Table 3: Comparison of laptop and control group unit marks

\begin{tabular}{|l|c|c|c|c|}
\hline & Assignment 1 & Assignment 2 & Exam & Total \\
\hline Laptop group ( $\mathrm{n}=45)$ & 69.96 & 61.30 & 62.13 & 64.15 \\
\hline Control Group $(\mathrm{n}=183)$ & 72.16 & 63.05 & 65.50 & 66.51 \\
\hline Difference & 2.20 & 1.75 & 3.37 & 2.36 \\
\hline
\end{tabular}

Figure 1 indicates the learning activities in which the students were engaged during the semester. The most common activities (over $70 \%$ of 
students) of showing presentations, taking notes, working in groups and accessing the library were enhanced by the use of the laptop computer and would not have been engaged in to as great an extent in the absence of the laptops.

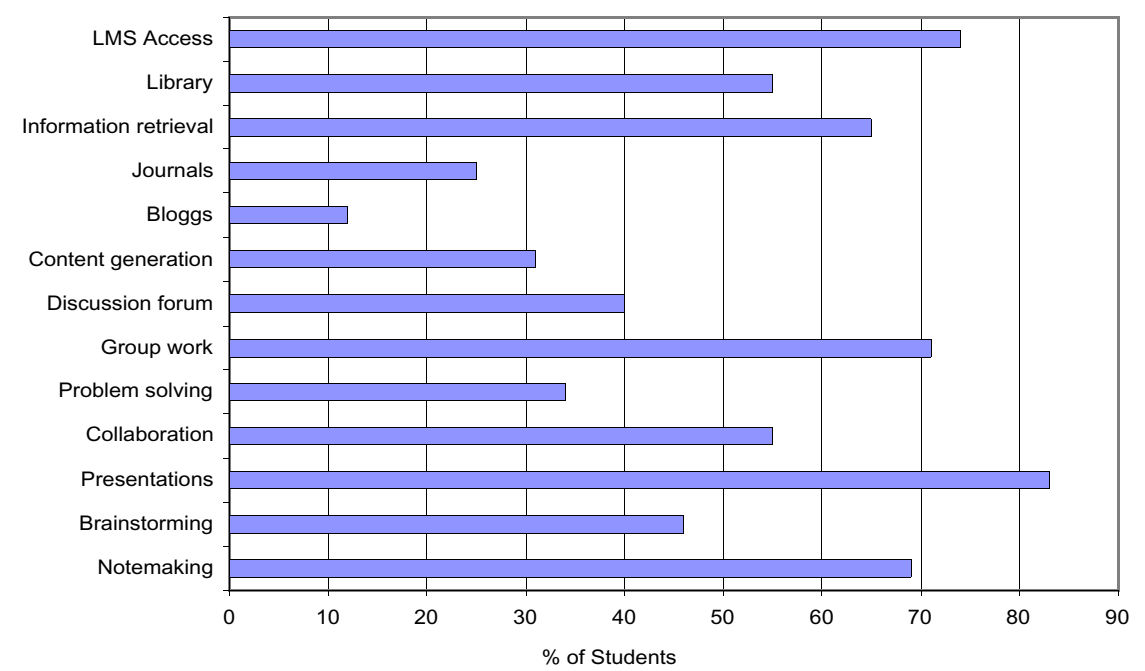

Figure 1: Learning activities

The data represented in Figure 2 shows the personal and social activities for which students used their laptops during the semester. The convenience of portable email and web access enhanced the students' overall experience in this class for the semester, and no doubt contributed to their desire to retain their laptops at the end of the semester.

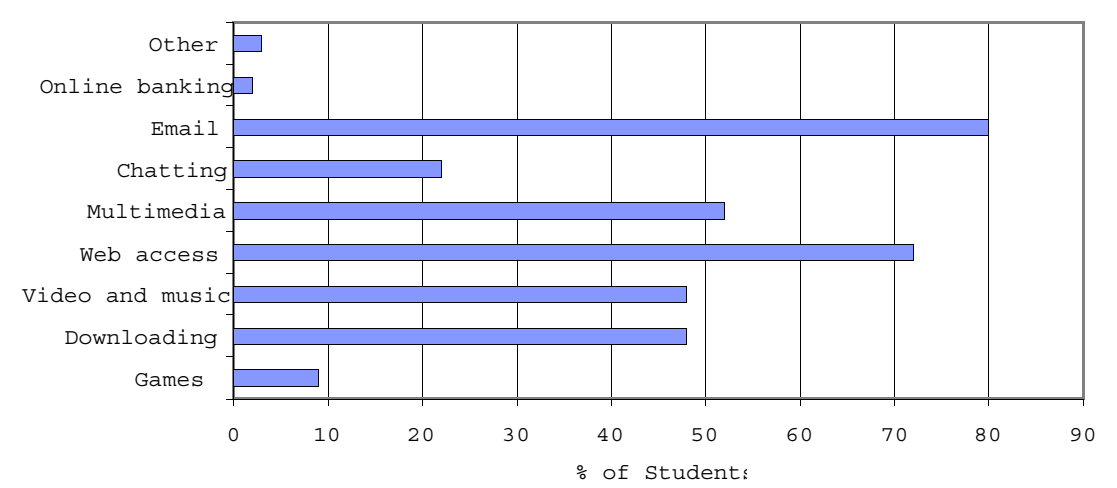

Figure 2: Personal and social activities 
The student's reflective discussions in their e-folio journals and their chats on the bulletin board were relatively unstructured and therefore wide ranging. Relevant discussions were extracted and analysed for common issues, patterns and themes.

Initially, the majority of students were nervous and worried about the responsibility of being allocated a laptop. Their concern related to both the practical aspects of caring for the hardware, and also the expectations they felt would be upon them in achieving the course outcomes at a high level. The few who were initially excited by the project were soon joined by the others who quickly overcame their concerns.

I felt overwhelmed by the responsibility to begin with, but this feeling was soon overcome by that of convenience (TC).

The computers quickly became part of their lifestyle for many students, rather than just a tool to use in completing assignments. The convenience of working on projects at anytime and place was a significant advantage to the many students who were juggling family, work and study commitments. The fact that they could also play music and send emails represented a significant enhancement for some.

I have finished up assignments while sitting in my [broken down] car waiting for the RAC, and have searched the Internet for resources with the wireless connection whilst relaxing on the lawn in the sunshine at uni (EL).

Convenience had another dimension for some students whose working styles were complemented by the use of laptops. For example the student who develops design ideas on bits and pieces of paper, now puts those ideas where they belong as they arise.

Now I just pull out the laptop and put my idea straight into my assignment or whatever I'm working on at the time (EL).

The students completed a practicum in schools during the course of the semester in which they had the laptops, and many reflected that this was an opportunity to experiment with tools and activities to which they have not had access in the past. They used it as a tool to promote integration of technology across the curriculum in an authentic manner.

The computers were equipped with a range of software that was to be used in the technology unit. This was a source of initial trepidation for the students, but a very positive outcome by the end of the semester. The majority of students felt that their computer skills had developed more than if they did not have a laptop, and more than they expected.

I can't believe I know how to use so many software programs (DV) 
Not a lot of undirected student comment about the use of laptop computers was related to learning, but as one of the areas of study during the semester related to learning styles and multiple intelligences, some students picked up on this theme. The majority of students who commented identified themselves as preferring to learn by doing, and having a computer at hand all the time enabled them to use the technology to accomplish many tasks with which they would otherwise be less engaged. It also represented a significant time saving device, with less time being taken to access information, and include a wider range of resources in their tasks.

They also readily saw the application to their teaching and the students in their classes, who could also benefit from a diversity of learning activities because of the diversity of learning styles.

With this [laptop] I will be using my learning style of doing rather than reading or writing and feel that a lot of children in the classroom also have this learning style and will benefit from my new knowledge of these products $(\mathrm{SH})$.

There were some negative aspects to being involved in this project for some students, mainly relating to hardware and software rather than learning and study. The absence of a floppy disk drive was inconvenient for some students, as the digital cameras that were available for loan stored images on a floppy disk. A couple of students thought the computers ran too slow, particularly with all the virus and spyware detection software. There were a range of issues that students dealt with, varying from the student who went through seven laptops at the beginning of the semester before getting one that worked, to other students with 'nothing worth mentioning'. The most common complaint was the awkwardness and weight of carrying the computer and bag around each day. Another common complaint was the unreliability of the Internet link, both when used at home and in conjunction with the wireless network at university. One student concluded:

If its green, it's biology; if it stinks its chemistry; if it has numbers it's math; if it doesn't work it's technology (ME).

The preservice teachers were part of a larger cohort and the laptop provided for them presented advantages and disadvantages. There were no significant advantages for the laptop trial group in their overall marks for the unit, although many had indicated that the laptop made their assignment work easier. From the lecturers' perspective the provision of rich learning experiences to enhance student competencies and understandings about the use of computers as a learning tool in technology education in 30 hours of course work was a challenge. 


\section{Conclusions from this project}

The response by the students was overwhelmingly positive and they were appreciative of the access to software at times other than tutorial sessions, complementing their busy schedules of work, study and parenting. Over $90 \%$ of students felt that the laptop enabled them to learn more effectively as they became better organised. The students also acknowledged that this led them to become more independent in their learning because of the stimulation and excitement of using the laptop. It was gratifying to have acknowledgement from the group that the use of laptops within this unit provided them with a range of life learning skills for teaching in the future. For at least a quarter of these students, computers were not previously utilised to any great extent in their learning.

There were a range of positive outcomes including the students' claim that ready access to the technology enabled them accomplish many tasks with which they would otherwise be less engaged. Over $90 \%$ of the students claimed the laptops had either saved them time, helped improve their computer skills or helped them organise their work. Portability and convenience were overwhelmingly the most common advantages cited for having a laptop. Students were able to work whenever it was convenient for them, regardless of their location; they didn't have to line up for access to the general student computer laboratory, they could take notes from texts in the library straight into assignments and could do their homework while watching TV. The other most commonly mentioned advantage was having all the software they needed for class already installed on the computer. In general, it was said that the computers became part of the students' lifestyle, particularly when on teaching practicum, and assisted their understanding of the application of the technology to teaching and learning.

\section{Supporting students possessing limited ICT skills}

The second project associated with the ECU Advantage Project in the School of Education was conducted during the first semester in 2005 with a group of 25 students in the first year of a Bachelor of Education (Primary) course, who were each loaned an IBM laptop computer. The project aimed to complement a new unit, Becoming Multi Literate, with a focus on language, numeracy and ICT literacy. A major component of the unit required students to demonstrate competence in the use of personal computers and general office software. They were also required to use LessonLab, an online learning environment with video based tools, email and electronic portfolios. It was known that a proportion of the students would enter the unit with little or no background in computer use, some without access to a computer at home. In the past many of these students 
had failed, struggled or become negative about the course due to their lack of experience in the use of ICT. Therefore the project intended to select 25 of these 'at risk' students and provide them with an additional weekly workshop (on a Friday afternoon) and email and phone support in the use of a laptop computer to satisfy the requirements of their first semester units in the Bachelor of Education (Primary). This would also provide an adequate basis for them to address the ICT requirements of later units and generally cope with university life. The objectives and expected outcomes of the project were:

1. To support 25 students in successfully completing the ICT components of the Becoming Multi Literate unit.

2. To develop adequate confidence, knowledge and skill in the use of ICT for 25 students to become as capable as their peers in using ICT within their university course and life.

3. To determine what level of support is required by students with little ICT experience to develop adequate confidence, knowledge and skill in the use of ICT to become as capable as their peers in using ICT within their university course and life.

During the orientation week students were informed about the project and application forms were distributed. The plan was for students to nominate themselves and provide some supporting information about their level of skill and their current access to a computer at home. Using this information a selection of the 25 most deserving students was to be made. In fact there were only 26 applicants with two withdrawing their applications before the beginning of the project and therefore all students wanting a laptop were included. During the first two weeks of the semester students collected their laptops and completed the initial training workshop provided by the central project team. Throughout the rest of the semester these students were supported by an educational computing academic, using email and phone communications, and an extra weekly workshop. After the examination period at the end of the semester the students returned their laptops. During the one hour workshops the students completed activities involving skills in word processing, web publishing, spreadsheeting, slideshow production, video editing, the WindowsXP operating system, file management and web searching.

\section{Implementation of the intervention}

The rollout of the laptops went relatively smoothly with the orientation being more than adequate for students to gain valuable information, particularly through the explanations and demonstrations of the technical features of the equipment. Technical and procedural information was also provided in a paper based pack provided to students. Students generally 
stated that they were very happy with the level of support and appreciative of the opportunity afforded them. There were very few problems for students to overcome, these being mainly in connecting to the wireless network. Some students found the backpack too cumbersome and heavy and used other forms of packs to carry the laptops, or did not carry them around.

The main objective of the intervention was achieved with the students being supported in the use of the technology as required for the multiliteracy unit. In fact, through email and phone communications and the weekly workshop, the students were provided with experiences beyond the requirements of their course, with workshops on using email, word processing, creating graphs from spreadsheets, accessing information from the library, creating and editing movies, creating music and creating web pages. These were selected on that the basis that they would be of value in future course units and in their teaching practicum. Most of the students used the machines for increased access to digital materials through the learning management systems Blackboard and LessonLab (video based materials). In addition, a few requests were received for individual help with other university work.

The project ran to schedule, although a number of students dropped out of the program and returned their laptops during the semester. This appeared to be either because they had purchased another computer, or they had withdrawn from the unit, or did not want to attend the extra workshops held on Friday afternoons. Only 16 students remained in the project. Further, only about half the students were strictly in the target group of inexperienced users with little computer and Internet access at home. However, all the students who remained in the program found it beneficial, often because it allowed them to access the wireless network or have a dedicated computer, rather than sharing one with family members. Further, it helped them keep all their work together. Many of the students who benefited the most were in the target group.

All students completed an expression of interest that included questions related to their previous experience in using computers, their current access to computers at home, their reason for wanting to join the project, and a self evaluation of their level of skill in using computers for word processing, slideshow production, email, file management, Internet research, digital photography, and image editing. During the project students responded to email requests at various times that sought to determine their level of success in using the computers (e.g. email files as attachments). At the end of the project the students were asked to complete a short questionnaire that included some of the same items as the initial questionnaire with regard to their skills and attitudes towards using 
computers, but also asked them to reflect on the benefits and limitations of being involved in the project.

\section{Results from data analysis}

Twenty-seven students completed the first questionnaire. The reasons they indicated for wanting to be involved in the program could be distilled to four: not being able to afford a reasonable computer (12); possessing poor computer skills (8); a belief that it would help them in doing studies (5); and a desire to learn more about computer use (2). Some of those indicating that they could not afford to buy a computer referred to having a very old computer, or having to share a computer with many family members. Twenty of the students indicated they did not have a computer at home, by which they often meant that they had to share a computer, and 18 indicated not having access to the Internet at home.

Two questions focussed on their previous and current experience in using computers. Fifteen indicated having regularly used computers for three or more years. However, only seven indicated using the computer daily and at least ten used a computer only occasionally. So while those seven clearly were not in the target group, most of the remaining eighteen were. They were also asked to indicate the last computing class they had taken. A total of fifteen indicated 'nothing' and three indicated short courses such as touch typing, information technology and introduction to Powerpoint. Four had done TAFE or university classes and the remaining five had done a class at school. The final item in the questionnaire provided a rubric for self evaluation of skill in using computers for word processing, slideshow production, email, file management, Internet research, digital photography, and image editing. Across the group, competency was low in all skill areas with the best being $40 \%$ indicating competence in emailing.

A total of 43 email responses were received from eighteen of the students. Almost all of the remaining eight students in the project dropped out of the project within the first few weeks. One student sent five emails. Only five students returned the attachment. Most of the emails were to ask for help on specific skills in using the computers or were administrative in nature. In addition, the academic support person regularly emailed the group and responded to phone and face to face requests made by some students.

Of the sixteen students remaining in the project, only nine completed the final questionnaire with all indicating that the laptops had been very useful and with most interested in investigating how to continue to have access to one. In particular they referred to what they had learned about using computers, the increased flexibility for working, and being able to work at home, learning on a "need to know basis". There were very few complaints 
with the main one being the unreliability of the University's modem pool. Only two of these students had indicated in the initial questionnaire that they did not have a computer at home or have Internet access, although five indicated the home computer was more than five years old. There was no difference in overall skill level (on the skills listed in the initial questionnaire) between the group who continued and responded to the final questionnaire and the rest of the original group of students.

They were asked how often they used the laptops at home compared with another computer they may have at home. A summary of their responses is given in Figure 3. It was gratifying to note that most used the laptops daily, but not another computer. They were also asked to identify what they used the laptops for at home. The most common responses were word processing assignments (6) and using Internet technologies (eg. Blackboard, web searching and email) (5). Other tasks were using an instructional CD for a unit of study, printing, and image editing.

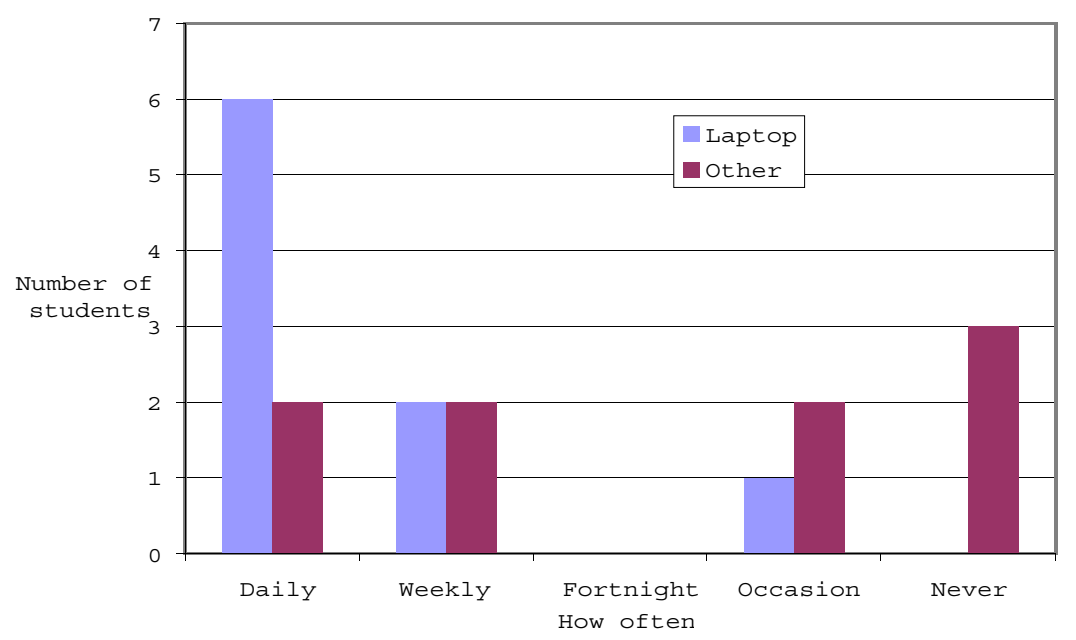

Figure 3: Students' frequency of use of the laptops and other computers at home

One question asked the students to indicate how often they used the laptops at University during the semester. A summary of their responses is given in Figure 4. Of concern was the fact that half the students indicated either only occasionally or never using the laptops at University (other than for the required one hour workshop associated with the project). This means they found no need to use the computers in their classes and clearly they used computer laboratory desktop computers for the unit that had computer workshops timetabled. They were asked what they used the 
laptops for at University, with the main responses being to type assignments and access the Internet between lectures (4), with only one student indicating some use in a lecture, and two specifically stating that they did not want to carry them around so they used the fixed laboratory computers.

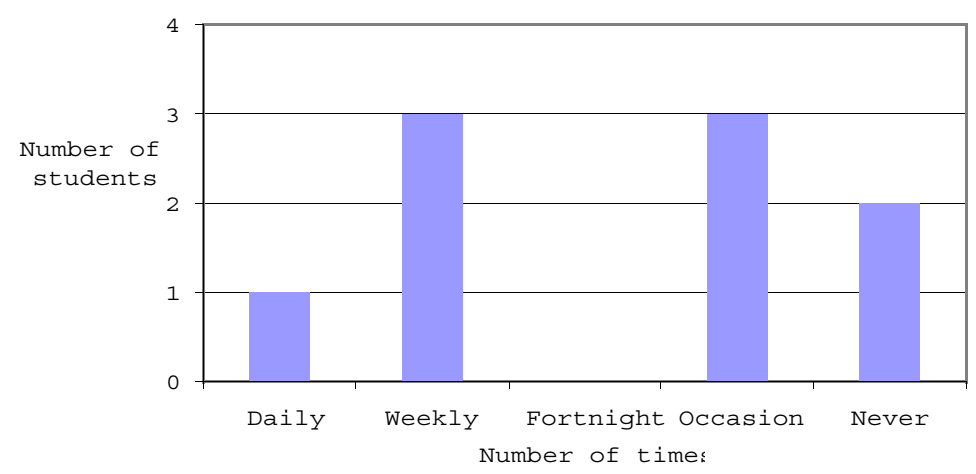

Figure 4: Students' frequency of use of the laptops at University

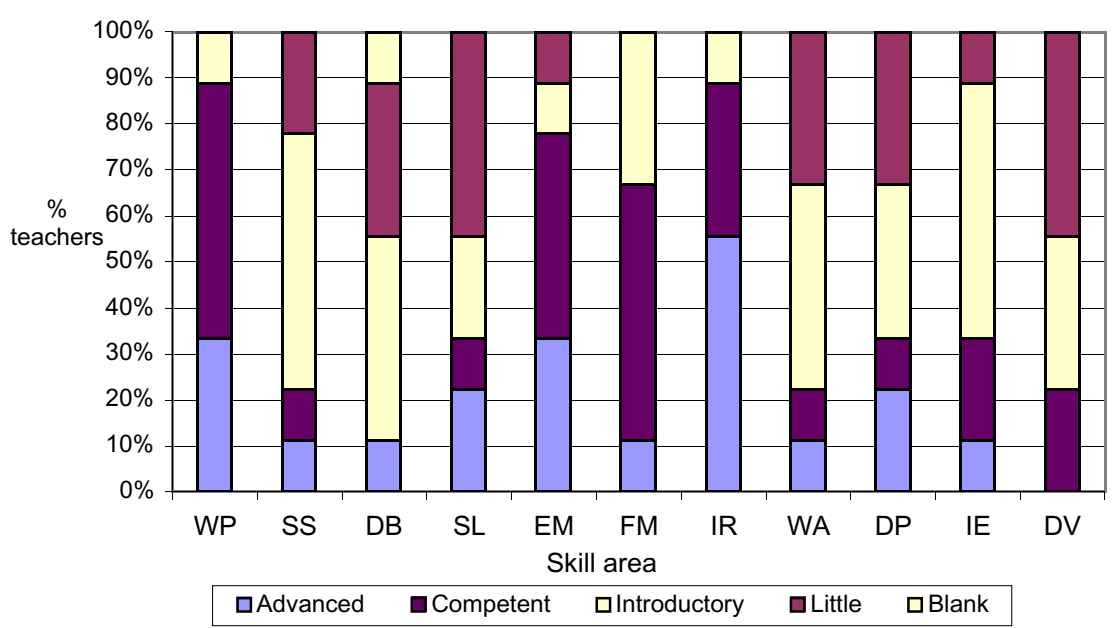

Figure 5: Self evaluation at the end of the project, of skill in using computers in a number of application areas

$\begin{array}{lllll}\text { Skill } & \text { WP } & \text { Word processing } & \text { IR } & \text { Internet research } \\ \text { areas } & \text { SS } & \text { Spreadsheet } & \text { WA } & \text { Web authoring } \\ & \text { DB } & \text { Database } & \text { DP } & \text { Digital photography } \\ & \text { SL } & \text { Slideshow } & \text { IE } & \text { Image editing } \\ & \text { EM } & \text { Email } & \text { DV } & \text { Digital video } \\ & \text { FM } & \text { File management } & & \end{array}$


The graph in Figure 5 presents a summary of their responses to the item requiring them to evaluate their own level of skill in using computers for 11 types of applications, including those from the initial questionnaire. When compared with the initial questionnaire clearly the competency of most of these students had improved, particularly in word processing, emailing, file management, and Internet research. A few of these students were also indicating competence in some of the other areas. Given that almost all of these students were those with poorer skills to start with (better students tended to drop out) this is a good result. A skills scale calculated by finding the mean rating across the skill areas common to the initial and final questionnaires gave a statistically significant $(t=3.24$, $\mathrm{p}<0.05$ ) increase in the mean for the group from 1.6 to 2.7 (where Advanced $=4$ and Little $=1$ ).

\section{Conclusions from this project}

The project was clearly worthwhile for those students who remained for the duration of the project. Their skills and confidence improved markedly and they all developed a positive view of computers as a valuable learning tool. As a result they all were concerned about how they would be able to maintain adequate access to computer processing. One difficulty with working with first year students is their lack of commitment to study and staying in the course. The attrition rate among first year education students is high, with many deciding to change courses or careers. Also of concern is the apparent lack of use of technologies within their classes, and for some the reluctance to carry the computers to University, most likely due to the weight and bulkiness of the laptops. Overall, the project achieved its original objectives for most of the 16 students who remained in it, with 12 passing the Becoming Multi Literate unit. Of those students who did not remain in the project, four withdrew from the course, and one failed the unit.

Most students used the computers for a range of unit related and social activities, particularly for online and multimedia based activities, including access to Blackboard and LessonLab materials. The latter was a major advantage to these students, as they had much more access to the video based material than other students. Almost certainly all of these students improved their confidence, knowledge and skill in the use of ICT, as illustrated in the increase in the mean of the ICT skills scale for those who completed the final questionnaire. They certainly developed to an extent adequate for the requirements of ICT use in their University course, and in some cases in skill areas beyond what would be expected of a first year student. It was clear that these students needed the combination of anytime access to a computer and the additional instruction provided through the weekly workshop and communication with an academic having 
appropriate expertise. While being loaned a laptop computer may not be the only way to provide the necessary anytime access, it certainly was sufficient and relatively efficient to organise.

\section{Discussion: Laptops or alternative mobile devices?}

While the outcomes from the exploratory studies were generally positive they were not overwhelmingly so, leaving the possibility that alternative mobile devices may be more appropriate. The main negative outcomes from the studies were the reluctance of students to carry a relatively heavy device when they were unlikely to be asked to use it in lectures and tutorials, and the purchase cost to the student or University in having a laptop computer, when desktop computers and other mobile devices are considerably cheaper. On the other hand it must be considered that they are most likely to use a laptop computer when teaching. The main options at this time are Personal Digital Assistants (PDA), limited purpose devices such as $i$ Pods, or multi-function mobile phones.

While laptop computers provide more convenient access to computer processing and communications for university students than desktop computers, they are still relatively expensive, large, heavy and often have battery lives less than required for a day's work. Personal Digital Assistants (PDAs) or hand held computers address these problems while giving most, but not all, the functionality of the laptop computer (McFadden, 2005). Initially they were designed to organise personal information, but now typically include operating, productivity and communications software compatible with desktop computers (Media and Methods Editor, 2004). According to Hudgins (2001), the use of PDAs by university students has become increasingly prevalent for tasks such as scheduling, note taking, downloading assignments and accessing the Internet. Keyboards can be attached so that they can input classroom notes, create writing summaries, do assignments and work on their keyboarding skills. Their handheld information can be downloaded to desktops for presentations, spreadsheets, documents and other digital materials (Media and Methods Editor, 2004). For teacher education students, it may become important to develop familiarity with PDA technology because it is likely that many teachers will use them as performance support systems to simplify paperwork for attendance, behaviour management and assessment (McFadden, 2005). They may also support students in schools in using the devices, although this is not dissimilar to using laptop computers. However, clearly the compelling reason for considering the use of PDAs is to support their learning at university, not as a means of providing them with skills and experience to incorporate the use of digital technology in their teaching practice. 
Apple's iPod is the best known of the MP3 digital music players which are an example of a limited purpose device. However, increasingly these devices are converging to produce multi-purpose devices, including a convergence with PDAs. The $i$ Pod was designed as a personal digital music player for the consumer market, but has been considered by some as a portable learning tool for dictation and sound recording, taking and reading notes, storing files and photos, and listening to audio books and newspapers (Apple Computer, 2005). One of the best known examples of these devices being used at a university was at Duke University in USA, where they were distributed to its incoming students in an effort to encourage innovative uses of technology in education and campus life (Roach, 2004). According to Grose (2004), iPods were used as teaching and learning tools, with the microphone allowing lectures and interviews to be recorded, and notes dictated. The devices were preloaded with audio and text material information for orientation and the academic calendar (Roach, 2004). Once again there are some good reasons for considering the use of a device such as an iPod to support learning at university, but not as a means of providing skills and experience to incorporate the use of digital technology in teaching practice. They tend to be cheaper, easier to use, and much more convenient to carry than PDAs, but provide much more limited functionality. As such, a PDA is probably more useful, given that the cost is only two or three hundred dollars more.

Mobile phones are probably the most ubiquitous electronic device in the world and therefore their use in education needs to be explored (Chen \& Kinshuk, 2005). Some have already found them useful as a new tutoring and communication medium (Galuszka, 2005; Virvou \& Alepis, 2005). The capabilities of mobile phones are expanding, allowing them to be used for wireless Internet to exchange voice messages, email, and small web pages, anywhere and anytime (Houser, Thornton, \& Kluge, 2002). There are situations where students could use some spare time constructively to finish off work in situations where no computer may be available (Virvou \& Alepis, 2005). Lecturers at Coventry University UK developed a teaching technique named 'm-learning', which allowed students to download course material and listen to lectures via their mobile phones (Okoli, 2005). By taking this concept a step further, lecturers at the university now send video clips, still images and sound clips to students' mobile phones. The potential low cost of mobile phones provides an attractive rationale for considering them as a learning tool for tertiary students although they still have relatively limited functionality. However, they provide little obvious potential at this time for preparing teacher education students to use digital technologies in their own teaching. 


\section{Conclusions}

Despite some dramatic recent developments in mobile technologies, the mobile devices and mobile networks still have some limitations compared to the desktop systems: the bandwidth of wireless networks is relatively low; the screen size is typically too small to display complex information, and the display of many devices in existence is monochrome; the CPU and memory capacity are both limited; they have limited input facilities and tend to be more expensive (Chen \& Kinshuk, 2005; Galuszka, 2005). The main advantages are clearly convenience (light, small, low powered and easy to use) and lower up front cost. For teacher education students they would all provide good support for learning, particularly PDAs, but would not provide adequate skills and experience to incorporate the use of digital technologies in the vast majority of Australian schools.

Clearly mobile education service systems can be a useful complement to the current desktop systems. Both the learners and the academics will benefit from these systems for convenient and instant access to resources and tools (Chen \& Kinshuk, 2005). With the rapid development of mobile technologies, future mobile devices will be much more powerful than current ones, and therefore continued evaluation of their benefits in teacher education will be needed. In particular, if the cost of mobile Internet access drops to a level affordable by typical students, then such systems become even more compelling. At this time it appears that either the comprehensive use of laptop computers or the use of PDAs in conjunction with desktop computers provides the best solution for teacher education programs, but at issue will be the extent to which students are required to carry the costs. The experience in our exploratory projects was that when the laptops were virtually free of cost to the students they were very positive, but this may not be the case when they are required to bear the costs themselves.

\section{References}

Apple Computer (2005). iPod in the Classroom. Apple Education Solutions. [viewed July 2005] http:/ / www.apple.com/education/ipod/

Blurton, C. \& Lee, A. (2002). Views of the first cohort of HKU notebook programme participants. Paper presented at the International Conference on Computers in Education (ICCE), Massey University, New Zealand.

Bradshow, A. L. \& Massey, J. (1996). Designing a virtual classroom through the use of laptop computers. Paper presented at the Annual International Conference of the National Community College Chair Academy.

Brown, D. G. (2003). Ubiquitous computing: The universal use of computers on college campuses. Bolton, MA: Anker Publishing Company. 
Cartwright, G. P. (1997). Three years and eight days - laptops for college students. Change, 29(4), 52-55.

Chen, J. \& Kinshuk (2005). Mobile technology in educational services. Journal of Educational Multimedia and Hypermedia, 14(1), 89-107.

Deden, A. (1998). Computers and systematic change in higher education. Communications of the ACM, 41(1), 58-64.

Finn, S. \& Inman, G. (2004). Digital unity and digital divide: Surveying alumni to study effects of a campus laptop initiative. Journal of Research on Technology in Education, 36(3), 297-318.

Galuszka, P. (2005). Technology's latest wave. Black Issues in Higher Education, 22(2), 24-26.

Gottfried, J. \& McFeely, M. (1998). Learning all over the place: Integrating laptop computers into the classroom. Learning and Leading with Technology, 25(4), 6-12.

Grose, T. (2004). Duke sings a new tune. ASEE Prism, 13(14).

Houser, C., Thornton, P. \& Kluge, D. (2002). Mobile learning: Cell phones and PDAs for education. Paper presented at the International Conference on Computers in Education (ICCE), Massey University, New Zealand.

Hudgins, B. (2001). Leveraging handheld technology in the classroom. THE Journal, 29(5), 46-47. [verified 29 July 2006] http:/ / thejournal.com/articles/15759

Kariuki, M. \& Turner, S. (2001). Creating electronic portfolios using laptops: A learning experience for preservice teachers, elementary school pupils, and elementary school teachers. Journal of Technology and Teacher Education, 9(4), 567584.

Lehner, F. \& Nosekabel, H. (2002). The role of mobile devices in e-learning--first experience with an e-learning environment. Paper presented at the IEEE International Workshop on Wireless and Mobile Technologies in Education, Los Alamitos, CA.

Mackinnon, G. (2001). A promising model for incorporating the computer in science learning. Journal of Mathematics and Science Teaching, 20(4), 395-404.

Mathiason, H. (2004). Expectations of technology: When the intensive application of IT in teaching becomes a possibility. Journal of Research on Technology in Education, 36(3), 273-294.

McFadden, A. (2005). A PDA primer. Principal Magazine, 82(1), 61.

McMillan, K. \& Honey, M. (1993). One year of project PULSE: pupils using laptops in science and English. New York: Center for Technology in Education.

Media and Methods Editor (2004). PDA handhelds: Improving student performance. Media and Methods, 41(1), 23-24.

Okoli, C. (2005). Coventry pilots 'm-learning' scheme. [viewed 11 Nov 2005] http://education.guardian.co.uk/elearning/story/0,10577,1482497,00.html 
Partee, M. H. (1996). Using e-mail, Web sites and newsgroups to enhance traditional classroom instruction. THE Journal. [verified 29 July 2006] http:/ / www.thejournal.com/articles/12459

Rideout, D. (2002). Laptops on the range! Education Canada, 42(2), 20-23.

Riggsby, D. (1998). Supporting student teachers with laptop computers: A project at the School of Education at Columbus State University. Paper presented at the Summer Conference, Association of Small Computer Users in Education, North Myrtle Beach, SC.

Roach, R. (2004). Incoming Duke freshmen receive Apple iPods. Black Issues in Higher Education, 21(20), 46.

Roschelle, J., Penuel, R. \& Abrahamson, L. (2004). The networked classroom. Educational Leadership, February, 50-54.

Schrum, L. \& Dehoney, J. (1998). Meeting the future: A teacher education program joins the information age. Journal of Technology and Teacher Education, 6(11), 23-37.

Thomas, L., Larson, A., Clift, R. \& Levin, J. (1996). Integrating technology in teacher education programs: Lessons from the Teaching Tele-apprenticeship Project. Action in Teacher Education, 17(4), 1-8.

Thompson, A., Schmidt, D. \& Davis, N. (2003). Technology collaboratives for simultaneous renewal in teacher education. Educational Technology Research and Development, 51(1), 73-89.

Vavoula, G. N. \& Sharples, M. (2002). KleOS: A personal, mobile, knowledge and learning organization system. Washington, DC: IEEE Computer Society.

Virvou, M. \& Alepis, E. (2005). Mobile educational features in authoring tools for personalised tutoring. Computers $\mathcal{E}$ Education, 44(1), 53-68.

Walker, T. \& White, C. (2002). Technorealism, the rhetoric and reality of technology in teacher education. Journal of Technology and Teacher Education, 10(1), 63-74.

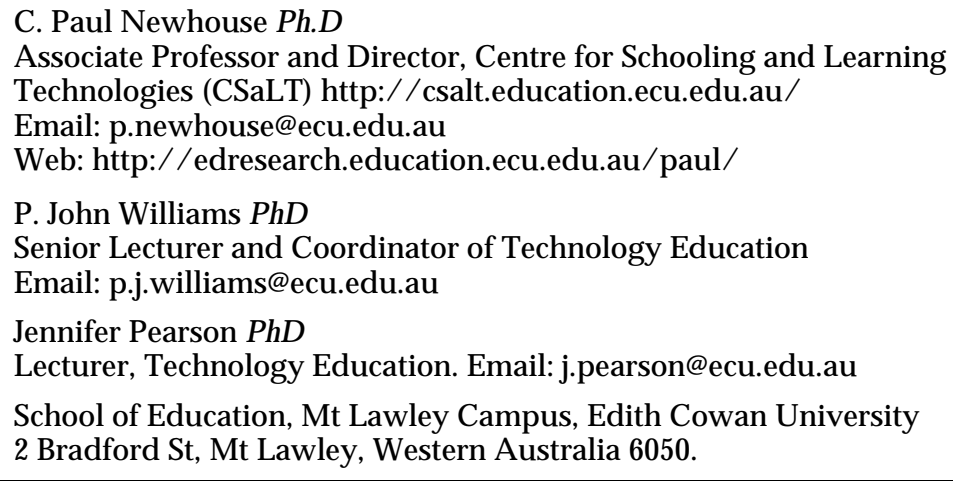

